\title{
Dietary Diversity, Iron Intake and Anemia among Pregnant Women in Embu County, Kenya
}

\author{
Nicoleta Mwaniki, Peter M Chege* and Ann Munyaka \\ Department of Food, Nutrition and Dietetics, Kenyatta University Kenya, Nairobi, Kenya
}

*Corresponding author: Chege PM, Department of Food, Nutrition and Dietetics, Kenyatta University, Nairobi, Kenya, E-mail: chegepeterm@ gmail.com

Received: 17 Jun, 2019 | Accepted: 22 Jul, 2019 | Published: 30 Jul, 2019

Citation: Mwaniki N, Chege PM, Munyaka A (2019) Dietary Diversity, Iron Intake and Anemia among Pregnant Women in Embu County, Kenya. Nutr Food Technol Open Access 5(1): dx.doi.org/10.16966/2470-6086.158

Copyright: (C) 2019 Mwaniki N, et al. This is an open-access article distributed under the terms of the Creative Commons Attribution License, which permits unrestricted use, distribution, and reproduction in any medium, provided the original author and source are credited.

\begin{abstract}
Iron deficiency anemia has been described as one of the most common nutritional deficiency during pregnancy. Dietary diversification has been described as an important food based strategy to meet iron need and involves the consumption of different types of foods from different food groups. Most pregnant women may have inadequate iron intake when their diet lack diversity and are dominated by staple starchy foods. There is minimal information on dietary diversity, iron intake and hemoglobin levels among pregnant women in Kenya. The purpose of this study was to establish dietary diversity, iron intake and hemoglobin levels among pregnant women in Embu County. The study adopted a cross-sectional analytical design with a sample of 172 systematically sampled pregnant women attending antenatal clinic in Embu level 5 hospitals in Embu County. Iron intake data was collected by use of 24-hour dietary recall and food frequency questionnaire. Dietary diversity questionnaire was used to gather data on dietary diversity. Blood samples were collected for hemoglobin estimation. Data from 24 hour dietary recall was analyzed using Nutri-survey. Chisquare tests were used to determine the relationship between variables. Statistical significance was set at a value of $p<0.05$. The study revealed that $22.4 \%$ of the participants were not meeting the minimum dietary diversity for women. About $45.7 \%$ of the pregnant women were not meeting the recommended daily allowances for dietary iron and $20.1 \%$ were anemic. A positive significant relationship was found between dietary diversity and hemoglobin levels, between iron intake and dietary diversity and between iron intake and hemoglobin levels. Dietary diversity is important in order to meet the dietary iron intake and be able to attain the required hemoglobin levels among pregnant women. Pregnant mothers who did not met the recommended Dietary Diversity Score (DDS) were 2.31 times more likely to be anemic that those who met. Regular consumption of a diversified diet among the pregnant women should be encouraged to prevent iron deficiency anemia during pregnancy.
\end{abstract}

Keywords: Dietary diversity; Iron intake; Hemoglobin levels; Pregnant women

\section{Introduction}

Iron is an essential nutrient that is vital in the body's tissues for basic functions of the muscles, brain and cells $[1,2]$. Iron is also an important constituent of hemoglobin in the red blood cells which is responsible for transportation of oxygen from the lungs to the cells. Iron supplies oxygen and nutrients to the fetus, supports placental functions and manufactures red blood cells [3]. Moreover, iron plays a vital role in the body's immune functions and is an important micronutrient for the development of the fetus brain and cognitive abilities of the new born [3]. Iron status is considered as a continuum from iron deficiency with anemia to iron deficiency with no anemia to normal iron status with varying amounts of stored iron [1]. Iron deficiency is as the result of the long terms negative iron balance during which iron stores are progressively diminished and can no longer meet the needs of normal iron turnover [3]. Iron deficiency is a condition in which there are no mobilizable iron stores. The more severe form of iron deficiency is associated with iron deficiency anemia [2]. Iron deficiency anemia is a condition in which the number of red blood cells and consequently their oxygen-carrying capacity is insufficient to meet the body's physiologic needs. Iron deficiency anemia during pregnancy is defined as hemoglobin level below $11 \mathrm{~g} / \mathrm{dl}$ at the sea level [4]. Pregnant women are recognized as one of the group most vulnerable to iron deficiency anemia because of increased iron requirements during pregnancy. The primary cause of iron deficiency anemia during pregnancy is iron deficiency a condition that is mostly caused by inadequate intake or low absorption of iron [5].

The number of anemic women in the world is estimated to be 56 million, with majority of them $(75-80 \%)$ being diagnosed with iron deficiency anemia [1]. It has been indicated that about $41.8 \%$ to $43.8 \%$ of pregnant women in the world are anemic and more than a half (57.1\%) of the pregnant women in Africa are anemic [1]. In Kenya, anemia in women of reproductive age is at $48 \%$ while anemia in pregnancy is at $55 \%$ [6]. A number of studies have shown that anemia during pregnancy has a significant impact on the health of 
the fetus and that of the mother $[7,8]$. The presence of severe anemia during pregnancy is said to limit the oxygen delivered to the placenta and the fetus thus affecting the intrauterine growth [8]. The weight, volume and surface area of the placenta are reduced if the pregnant woman is moderately anemic [7]. Moreover, anemia during pregnancy has been shown to result to about $20 \%$ to $28 \%$ of fetal loss, about $30 \%$ prenatal deaths and $7 \%$ to $10 \%$ of neonatal deaths [6,7]. Iron deficiency anemia negatively affects lives of many pregnant women and children leading to improper mental development besides contributing to high rates of maternal mortality and decreased work productivity among the pregnant women $[9,10]$. Iron deficiency anemia during pregnancy may also result to maternal deaths since anemic women are more likely to die from blood loss during delivery [8]. Anemia during pregnancy contributes to $20 \%$ of maternal deaths [8]. Due to the dire consequences of iron deficiency anemia during pregnancy it is important to ensure that iron deficiency whether severe, mild or moderate is eliminated to ensure the optimal health of the mother and the infant.

Dietary diversity is assessed as the number of foods consumed across and within food groups over a reference period and it is an important dimension of diet quality $[11,12]$. Lack of dietary diversity, leading to consumption of monotonous diet and inadequate consumption of fruits and vegetables and food from animal sources among pregnant women is the main contributor to under nutrition and thus iron deficiency anemia [13]. The consumption of a wide variety of foods across different food groups is a recommended strategy to help achieve adequate intake of dietary iron and improve iron status among the pregnant women. However, in Kenya, the diets are most of the time monotonous consisting of starchy staples, grains and cereals often lacking in vegetables, fruits and animal based foods which are rich in bioavailable iron. These monotonous diets therefore contribute to inadequate dietary iron intake among pregnant women. Moreover, the predomination of the diets of pregnant women by cereals and legumes in Kenya is a concern because these foods are rich in non-heme, iron which is less bio-available compared to heme iron from animal based foods $[6,14]$.

Dietary diversity has been recognized as a long term measure towards the prevention of iron deficiency anemia and other micronutrients deficiency $[15,16]$. However, the association between dietary diversity, iron intake and hemoglobin levels among pregnant women in Kenya has not been adequately documented. Therefore, there is limited literature with regard to dietary diversity, iron intake and hemoglobin levels among pregnant women in Kenya, more so in Embu County. This study was therefore carried out to determine dietary diversity, iron intake and hemoglobin levels among pregnant women so as to increase knowledge in this area. In addition, there may be other maternal factors that may affect dietary diversity and thus iron intake and hemoglobin levels among pregnant women that are not adequately documented. Therefore the present study sought to address these gaps by determining the dietary diversity, iron intake and hemoglobin levels among pregnant women and identifying factors influencing the dietary diversity, iron intake and hemoglobin levels among pregnant women in Embu County. Such information will add to the existing body of knowledge and is valuable towards improving dietary diversity, iron intake and hemoglobin levels among pregnant women by the program implementers.

\section{Methods}

The study adapted a cross-sectional analytical study design. The study was carried out at Embu level five hospitals in Embu County. Embu level five hospitals are located in Embu town which is the Embu county headquarters. Embu County is in the Eastern region of Kenya and borders Kirinyaga to the West, Kitui to the East, and TharakaNithi to the North and Machakos to the south. The target population for this study was pregnant women who were visiting the Mother and Child Health $(\mathrm{MCH})$ clinic at Embu level five hospitals at the time of the study. Only pregnant women attending Embu level five hospitals $\mathrm{MCH}$ clinic who gave informed consent were included in the study. Pregnant women who were chronically ill as established from health record from the hospital were excluded from the study.

Embu level 5 hospitals were purposively selected because it is the major referral hospital getting referrals Embu County and the neighboring counties of Kirinyaga and Tharaka-Nithi. Systematic sampling was used to select the sample based on hospital records. The sampling was collected from Monday to Friday within a period of one month during the research period until the required sample was obtained. The sample size of the study was 172 calculated using the formula $\left(\mathrm{n}=\mathrm{Z}^{2} \mathrm{pq} / \mathrm{e}^{2}\right)$ by Israel [17].

Data was collected using a researcher administered structured questionnaire. The dietary diversity data was collected by use of structured dietary diversity questionnaire, which was adapted from Food and Agriculture Organization (FAO) [10]. The dietary diversity questionnaire was adjusted to include the locally available foods. The dietary diversity questionnaire included 10 food groups. The questionnaire was pre-tested to check on the content, the wording, the language, the length and for any omissions and corrections. The pre-testing sample for the questionnaire included 17 pregnant women (10\% of the sample size) attending Majimbo health centre in Embu County.

The researcher and the research assistants visited the $\mathrm{MCH}$ clinic in Embu level-5 hospital daily for a period of one month during April 2015. With the help of the nurse in charge the researcher recruited the research participants and then explained the purpose, objectives and the procedure of the study to the respondents. The questionnaire was administered to women who gave informed consent by signing to participate in the study. The interview was conducted after the pregnant women had been given the routine antenatal care services.

The dietary diversity questionnaire was used to collect information on all the foods and the drinks that were consumed by the individual pregnant women for the last 24 hour period [16]. The food and drinks that were reported by the participants were then recorded in a ten food group questionnaire which was used to calculate the minimum dietary diversity for women. A 24 hour dietary recall questionnaire was used to collect data on all the food, snacks and drinks consumed the previous day including details on the time of the meal, the place the meal was consumed, details of the method of preparation and the amount consumed. The 24 hour dietary recall questionnaire was administered at the first time at the $\mathrm{MCH}$ clinic and then it was repeated in the houses of the study participants in order to confirm the household measurements. Household's utensils such as glasses, cups, bowls, tablespoons, teaspoons, serving spoons, plates were used to estimate the amount of food and drinks consumed by the respondents. Fruits, which were on season were purchased and used for estimation of portions sizes. Vegetables were purchased and cooked for portion estimation. Probing was used to ensure that no food or drinks was forgotten. Respondents were also asked whether they consumed the food from their home or from outside.

A seven day food frequency questionnaire was used to collect data on the number of times the reported food items were consumed per week. The food frequency table included the food items, which were 
readily available in the market during the period of the study and the respondents were asked the number of times they consumed a given food per week and the number of times the foods items were consumed was recorded in the questionnaire. A list of 77 commonly consumed food items was made and the respondents were asked to state the number of days they consumed each of the food in a week. Consumption of a food for at least thrice a week was considered to be regular intake while consumption of a food for less than 3 days was considered to be irregular consumption $[18,19]$.

The hemoglobin levels of the respondent were assessed using the hemoglobin concentration in their blood. The hemoglobin concentration of the pregnant women was determined using HemoCue B-Hemoglobin analyzer. A laboratory technician who was part of the research team did the hemoglobin test in Embu level five laboratories. The assessment of hemoglobin was conducted according to a previously published procedure. The procedure involved, assembling required supplies at the respondent location, removing the appropriate number of cuvette from the vial and then place the cap back on vial promptly. The whole blood sample was then obtained by finger prick into the microcuvette. The filled microcuvette was placed in the cuvette holder and pushed in to its measuring position. After approximately 15-60 seconds the hemoglobin value of the sample would be displayed on the window. The microcuvette was removed and disposed of in the appropriate container. The hemoglobin levels for each of the respondent were immediately recorded in the laboratory request form and later on the questionnaire.

Data was entered in Microsoft excel and then exported to SPSS version 16 for analysis. Data from 24 hour dietary recall was analyzed using the nutrisurvey software. Dietary diversity was based on ten food groups used to measure the Minimum Dietary Diversity for Women (MDDW). The pregnant women who did not consume food from at least five food groups were classified as not meeting the minimum dietary diversity for women while those consuming food from five food groups or more were considered as having met the minimum dietary diversity for women. Iron deficiency anemia in this study was classified using the world health organization classification [2]. A hemoglobin value of less than $7.0 \mathrm{~g} / \mathrm{dl}$ was classified as severe anemia, while hemoglobin value of between 7.0 and $9.9 \mathrm{~g} /$ $\mathrm{dl}$ was classified as moderate anemia. Further a hemoglobin value of between 10 and $10.9 \mathrm{~g} / \mathrm{dl}$ was classified as mild anemia while a hemoglobin value of equal to or greater than $11 \mathrm{~g} / \mathrm{dl}$ was classified as non-anemic [2]. To determine association between variables Pearson correlation and chi-square tests were used. A p-value of $<0.05$ was considered statically significant.

\section{Results}

The estimated sample size was 172 but only a total of 164 pregnant women fully participated in the study.

\section{Demographic and socio-economic characteristics of the respondents}

Most of the study participants were young with majority (35.4\%) being between 25-29 years. Majority (77.1\%) of the respondents were primiparous. Large proportions $(88.4 \%)$ of the respondents were married. Concerning education level, most (68.3\%) of the participants had attained secondary education. Most of the respondents (31.7\%) were in the second wealth quartile followed by $25.6 \%$ who were in the low wealth quartile. A very small proportion of the respondents (9.8\%) were found to be in the highest wealth quartile.

\section{Dietary intake among the pregnant women based on dietary diversity}

The dietary diversity for the respondents was calculated based on the MDDW which comprised of ten food groups as recommended by FAO [20]. Most of the study participants (72.6\%) had met the minimum dietary diversity for women since they were consuming foods from more than five food groups. About $27.4 \%$ had not met the minimum dietary diversity for women since they were consuming food from less than 5 food groups (Figure 1).

The mainly consumed food groups based on the 10 food groups were; grains, white roots, tuber and plantains and other vegetables which were consumed by $100 \%$ of the study participants. Meat, poultry and fish were consumed by only $39.6 \%$ of the respondents while nuts and seeds were consumed by only $30.5 \%$ of the respondents (Table 1 ).

\section{Dietary intake of selected nutrients among pregnant women}

The mean energy intake of the respondents was $2263 \pm 94.9$ kilocalories with values ranging from 2100 to 2426 kilocalories. Majority of the respondents (86.6\%) met the Recommended Dietary Allowance (RDA) for energy from their diet. About $81.7 \%$ of the study participants had adequate proteins from their diet with a mean consumption of $74.4 \pm 2.5 \mathrm{~g}$ with consumption ranging from 51.3 to 105.6 g. Notably slightly more than half $(54.3 \%)$ of the respondents were meeting the RDA for iron with a mean intake of $29.9 \pm 5.1 \mathrm{mg}$ with intake ranging from 17.3 to $41.12 \mathrm{mg}$ (Table 2). As per other nutrients, intake was adequate for $>70 \%$ of respondents except for zinc (57.9\%) and vitamin B12 (66.5\%).

\section{Hemoglobin levels of the pregnant women}

Blood hemoglobin concentration was used to assess anemia of the pregnant women and women with hemoglobin levels of less than $11 \mathrm{~g} / \mathrm{dl}$ were classified as being iron deficient [5]. About $4.3 \%$ of the respondents had a hemoglobin level between 7.1 and $10 \mathrm{~g} / \mathrm{dl}, 15.9 \%$ had hemoglobin levels ranging from $10.1 \mathrm{~g} / \mathrm{dl}$ and $10.9 \mathrm{~g} / \mathrm{dl}$ while $76.9 \%$ had hemoglobin level between $11.1 \mathrm{~g} / \mathrm{dl}$ and $12 \mathrm{~g} / \mathrm{dl}$. In this study, $20.1 \%$ of the respondents were found to be anemic (Table 3).

\section{Relationship between variables}

Pregnant mothers who did not met the recommended DDS were 2.31 times more likely to be anemic that those who met (Table 4).

Positive significant relationships were found between MDDW and hemoglobin level $(\mathrm{r}=0.48, \mathrm{p}=0.041)$ and iron intake and MDDW $(\mathrm{r}=0.57, \mathrm{p}=0.038)$. In addition, positive relationships were obtained between the pregnant women's iron intake and their hemoglobin levels $(\mathrm{r}=0.54, \mathrm{p}=0.031)$ (Table 5).

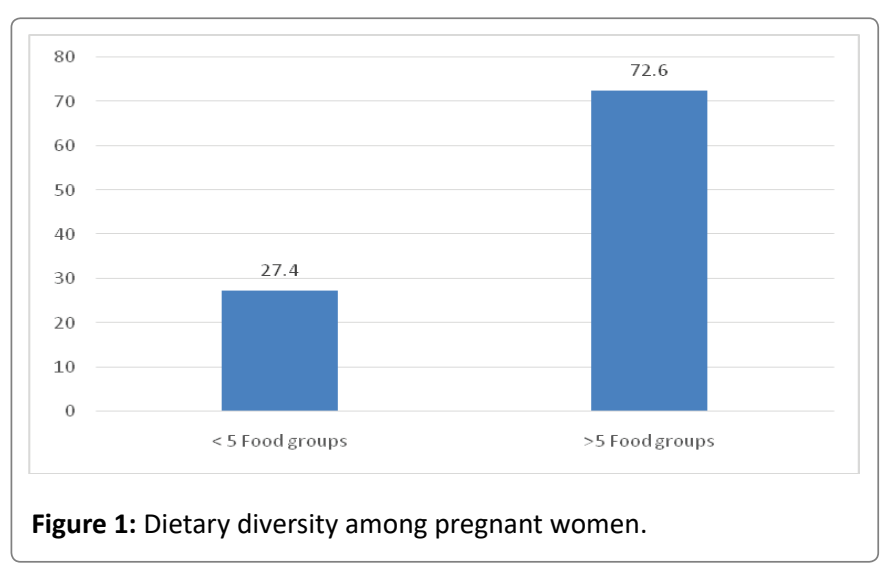


Table 1: Dietary intake among the pregnant women based on ten food groups.

\begin{tabular}{|l|c|c|}
\hline \multicolumn{1}{|c|}{ Food Groups } & \multicolumn{2}{c|}{ n (164) } \\
\hline Grains, white roots and tuber and plantains & 164 & 100 \\
\hline Pulses (beans, peas and lentils) & 153 & 93.3 \\
\hline Nuts and seeds & 50 & 30.5 \\
\hline Dairy & 153 & 93.3 \\
\hline Meat, poultry and fish & 65 & 39.6 \\
\hline Eggs & 137 & 83.5 \\
\hline Dark green leafy vegetables & 104 & 63.4 \\
\hline Other Vitamin A-rich fruits and vegetables & 121 & 73.8 \\
\hline Other vegetables & 164 & 100 \\
\hline Other fruits & 153 & 93.3 \\
\hline
\end{tabular}

Table 2: Proportion of respondents estimated to be consuming sufficient amount of selected macronutrients and micronutrients.

\begin{tabular}{|c|c|c|c|c|c|c|}
\hline \multirow{2}{*}{ Nutrients } & \multicolumn{6}{|c|}{ Respondents meeting RDA } \\
\hline & $\mathbf{n}$ & $\%$ & RDA & Mean & Minimum & Maximum \\
\hline Energy (Kcal) & 142 & 86.6 & 2350 & $2263.0 \pm 94.9$ & 2100 & 2426 \\
\hline Protein (g) & 134 & 81.7 & $60-80$ & $72.4 \pm 20.3$ & 51.3 & 105.6 \\
\hline $\begin{array}{l}\text { Vitamin A } \\
\text { (IU) }\end{array}$ & 135 & 82.3 & 2500 & $68.6 \pm 2.5$ & 42.3 & 78.5 \\
\hline Zinc ( mg) & 95 & 57.9 & 12 & $13.3 \pm 1.9$ & 9.2 & 17.8 \\
\hline $\begin{array}{l}\text { Folic acid } \\
(\mathrm{mg})\end{array}$ & 121 & 73.8 & 4 & $4.94 \pm 1.02$ & 2.1 & 7.8 \\
\hline Iron (mg) & 89 & 54.3 & 30 & $29.9 \pm 5.1$ & 17.3 & 41.12 \\
\hline $\begin{array}{l}\text { Vitamin B1 } \\
\text { (mg) }\end{array}$ & 121 & 73.8 & 1.4 & $1.51 \pm 0.7$ & 0.6 & 2.6 \\
\hline $\begin{array}{l}\text { Vitamin B2 } \\
\text { (mg) }\end{array}$ & 109 & 66.5 & 1.4 & $1.63 \pm 0.7$ & 0.8 & 2.82 \\
\hline $\begin{array}{l}\text { Magnesium } \\
\text { (mg) }\end{array}$ & 135 & 82.3 & 400 & $288.4 \pm 8.9$ & 236.4 & 625.3 \\
\hline $\begin{array}{l}\text { Calcium } \\
\text { (mg) }\end{array}$ & 150 & 91.5 & 1500 & $\begin{array}{c}1560.6 \pm \\
14.5\end{array}$ & 1140.1 & 1786.6 \\
\hline $\begin{array}{l}\text { Selenium } \\
\text { (mg) }\end{array}$ & 106 & 64.6 & 60 & $62.2 \pm 1.8$ & 52.3 & 71.6 \\
\hline $\begin{array}{l}\text { Vitamin C } \\
(\mathrm{mg})\end{array}$ & 152 & 92.7 & 85 & $90.6 \pm 0.9$ & 74.2 & 98.3 \\
\hline $\begin{array}{l}\text { Vitamin B12 } \\
\text { (mg) }\end{array}$ & 149 & 90.9 & 2.6 & $3.01 \pm 0.4$ & 2.03 & 3.9 \\
\hline $\begin{array}{l}\text { Vitamin B6 } \\
\text { (mg) }\end{array}$ & 138 & 84.1 & 1.9 & $2.2 \pm 0.05$ & 1.08 & 2.75 \\
\hline
\end{tabular}

Table 3: Hemoglobin levels of the pregnant women.

\begin{tabular}{|c|c|c|c|}
\hline \multirow{4}{*}{$\begin{array}{c}\text { Hemoglobin level } \\
\text { (g/dl) }\end{array}$} & $7.1-10.0$ & 7 & 4.3 \\
\cline { 2 - 4 } & $10.1-10.9$ & 26 & 15.9 \\
\cline { 2 - 4 } & $12-$ Nov & 126 & 76.9 \\
\cline { 2 - 4 } & $>12.1$ & 5 & 3 \\
\hline \multirow{2}{*}{ Anemia status } & Anemic & 33 & 20.1 \\
\cline { 2 - 4 } & Non-anemic & 131 & 79.9 \\
\hline
\end{tabular}

Table 4: Association between dietary diversity and hemoglobin levels.

\begin{tabular}{|l|c|c|c|c|}
\hline \multicolumn{5}{|c|}{ DDS status } \\
\cline { 1 - 4 } & Anemic & Non-anemic & Total & \\
\cline { 1 - 4 } Met DDS & 7 & 112 & 119 & \multirow{2}{*}{$\begin{array}{c}\text { OR=2.31; } \mathrm{p}<0.001 \\
\mathrm{Cl}, 1.35 \text { to } 10.55\end{array}$} \\
\cline { 1 - 4 } Did not Met DDS & 26 & 19 & 45 & \\
\cline { 1 - 4 } Total & 33 & 131 & 164 & \\
\hline
\end{tabular}

Table 5: Relationship between study variables.

\begin{tabular}{|l|l|c|c|}
\hline & \multicolumn{1}{|c|}{ Variables } & r & p-value \\
\hline \multirow{2}{*}{ MDDW } & Iron intake & 0.57 & 0.038 \\
\cline { 2 - 4 } & Hemoglobin level & 0.48 & 0.041 \\
\hline \multirow{2}{*}{ Hemoglobin (HB) } & Iron Intake & 0.54 & 0.031 \\
\cline { 2 - 4 } & MDDW & 0.48 & 0.041 \\
\hline \multirow{2}{*}{ Iron intake } & Hemoglobin & 0.54 & 0.031 \\
\cline { 2 - 4 } & Dietary diversity & 0.57 & 0.038 \\
\hline
\end{tabular}

\section{Discussion}

A high proportion $(72.6 \%)$ of the study participants had met MDDW. The most consumed food groups by the study participants were; the grains, white roots, tuber and plantains and other vegetables, which were consumed by $100 \%$ of the respondents. Nuts and seeds were the least consumed food groups by $<31 \%$. Notably food rich in heme iron such as fish, chicken and meat were not regularly consumed, being consumed by less than half $(39.7 \%)$ of the respondents. The finding of this present study agrees with another study that pointed out that diets of women in developing countries lack or have little animal based foods [6]. A high proportion of the respondents also reported to consume maize and its products, wheat and its products and legumes regularly. This study findings are in agreement with other studies that have pointed out that diet of most pregnant women in developing countries is predominantly based on cereals, legumes and grains [14]. Tea was regularly consumed by $82.3 \%$ of the respondents and $65 \%$ of the respondents reporting to consume it along with meals. This was in agreement with another study carried out among pregnant women attending Pumwani hospital which reported that (93.4\%) of the pregnant regularly consumed beverages (tea, cocoa or coffee) and (66\%) of them drink these beverages in less than 20 minutes before or after meals [12]. In this study, slightly more than a half (54.3) of the participants was meeting the RDA for iron while less than a half (45.7\%) was not meeting their RDA for iron.

The present study findings revealed that $20.1 \%$ of the participants were anemic a value lower than the global (43.8\%) and Kenyan national (55.1\%) values [6]. Regarding anemia prevalence, values differing from those observed in the current study were previously reported in different studies. Previous studies conducted in other counties including; Nairobi, Kakamega and Laikipia reported anemia prevalence of $73.6 \%, 57 \%, 40 \%$ and $16.9 \%$, respectively $[6,14,15]$. The present study findings regarding anemia prevalence are also in contrast with finding obtained in studies carried out in other African countries which reported anemia prevalence values of $63 \%$ in Uganda [21], 62.2\% in Egypt [22], 56.8\% in Ethiopia [20], 54.6\% in Nigeria [23] and $47.4 \%$ in Tanzania [24] among pregnant women. The current study findings are however, comparable to those reported in a study carried out in Mekelle town in Ethiopia which indicated that the 
overall prevalence of anemia among pregnant women was 19.7\% [25]. Anemia prevalence value lower than that observed in the current study has also been reported in Sudan [26].

The relatively low prevalence of anemia noted among the pregnant women in the present study would be explained by the fact that a higher proportion of the respondents were achieving the minimum dietary diversity and were consuming food items from more than five of the ten food group used in determining the minimum dietary diversity for women. These findings are in agreement with another study that women who consume food items from five or more of the ten food groups have a higher likelihood of having a higher micronutrient adequacy [16]. In addition, a higher prevalence of MDDW is a proxy for better micronutrients including iron adequacy among pregnant women [16].

In the current study, a positive significant relationship was found between dietary diversity and iron intake and between hemoglobin level and dietary diversity of the pregnant women. A higher proportion of the participant in this study had achieved the minimum dietary diversity for women. These findings are in agreement with other studies that have pointed out that all dietary diversity scores are a proxy measure of micronutrient adequacy of the diet including that of women of reproductive age in general and that of pregnant women. Moreover, dietary diversity is positively associated with a diet which is adequate in essential micronutrients including iron [10,27]. The present study finding showed positive correlations between dietary diversity and iron intake of $(\mathrm{r}=0.5, \mathrm{p}=0.038)$ and positive correlation of $(r=0.48, p=0.041)$ between dietary diversity and hemoglobin levels of the pregnant women. All these positive significant correlations in this present study are in agreement with other studies which have shown that a diversified diet is associated with micronutrients adequacy [2830]. Moreover, when an individual consumes different foods or food items among and within the various food groups it promotes sufficient intake of essential micronutrients from the diet [30,31]. A study in Nairobi, Kenya [6] and in Laikipia, Kenya [14] found that pregnant mothers who did not met the recommended DDS being twice more likely to be anemic that those who met just like in this study.

\section{Conclusion}

The study showed that the dietary diversity of the pregnant women was high with more than half of the participant having met the minimum dietary diversity. The dietary iron intake among the pregnant women was not very satisfactory with slightly more than a half of the women meeting the RDA for iron. Based on hemoglobin levels $20.1 \%$ of study participants were anemic. Some women (27.4\%) did not the MDDW. Positive significant associations were found between dietary diversity, iron intake and hemoglobin levels. This underscores the importance of a diversified diet in meeting the iron requirement of the women in order to be able to meet the iron requirement during pregnant as well as achieve the recommended hemoglobin levels during pregnancy.

\section{Recommendations}

This study recommends continued sensitization for regular consumption of a diversified diet among the pregnant women to prevent iron deficiency anemia during pregnancy.

\section{Ethical Approval}

Ethical clearance was obtained from Ethical Review Committee from Kenyatta University. Research Permission was sought from the county government and from the hospital administration. Informed and signed consent was sought from the respondents.

\section{Competing Interests}

The authors declare that they have no competing interests.

\section{Funding}

The research was funded by the researchers.

\section{Acknowledgement}

The authors would like to thank all the pregnant women who participated in the research.

\section{References}

1. McLean E, Cogswell M, Egli I, Wojdyla D, de Benoist B (2009) Worldwide prevalence of anaemia, WHO vitamin and mineral nutrition information system, 1993-2005. Public Health Nutr 12: 444-454.

2. WHO, UNU, UNCF (2007) Iron Deficiency Anemia Assessment Prevention and Control: A guide for Program Managers. Geneva, Switzerland.

3. Gropper SS, Smith JL (2012) Advanced nutrition and human metabolism. $6^{\text {th }}$ Edition, Cengage Learning, University of Delaware 608.

4. Kumar R (2015) Iron deficiency anemia (IDA), their prevalence, and awareness among Girls of reproductive age of Distt Mandi Himachal Pradesh, India. Int Lett Nat Sci 29: 24-32.

5. Stevens GA, Finucane MM, De-Regil LM, Paciorek CJ, Flaxman SR, et al. (2013) Global, regional, and national trends in haemoglobin concentration and prevalence of total and severe anaemia in children and pregnant and non-pregnant women for 1995-2011: a systematic analysis of population-representative data. Lancet Glob Health 1: e16-e25.

6. Okube OT, Mirie W, Odhiambo E, Sabina W, Habtu M (2016) Prevalence and factors associated with anaemia among pregnant women attending antenatal clinic in the second and third trimesters at pumwani maternity hospital, Kenya. Open J Obstet Gynecol 6: 16-27.

7. Akhtar M, Hassan I (2012) Severe Anaemia during Late Pregnancy. Case Rep Obstet Gynecol 2012: 485452.

8. Raza N, Sarwar I, Munazza B, Ayub M, Suleman M (2011) Assessment of iron deficiency in pregnant women by determining iron status. J Ayub Med Coll Abbottabad 23: 36-40.

9. Kenya National Bureau of Statistics, ICF Macro (2010) Kenya Demographic And Health Survey 2008-09. KNBS and ICF Macro, Calverton, Maryland, USA.

10. Olumakaiye MF (2013) Dietary diversity as a correlate of under nutrition among school-age children in southwestern Nigeria. J Child Nutr Manag 37.

11. Arimond $\mathrm{M}$, Wiesmann $\mathrm{D}$, Becquey $\mathrm{E}$, Carriquiry $\mathrm{A}$, Daniels $\mathrm{MC}$, et al. (2010) Simple food group diversity indicators predict micronutrient adequacy of women's diets in 5 diverse, resource-poor settings. J Nutr 140: 2059S-2069S.

12. Kennedy G, Fanou-Fogny N, Seghieri C, Arimond M, Koreissi Y, et al. (2010) Food groups associated with a composite measure of probability of adequate intake of 11 micronutrients in the diets of women in urban Mali. J Nutr 140: 2070S-2078S.

13. Hassan AA, Mamman Al, Adaji S, Musa B, Kene S (2014) Anemia and iron deficiency in pregnant women in Zaria, Nigeria. Sub-Saharan Afr J Med 1: 36-39. 
14. Willy K, Judith K, Peter C (2016) Dietary Diversity, Nutrient Intake and Nutritional Status among Pregnant Women in Laikipia County, Kenya. Int J Health Sci Res 6: 378-385.

15. Siteti MC, Namasaka SD, Ariya OP, Injete SD, Wanyonyi WA (2014) Anaemia in pregnancy: Prevalence and Possible Risk Factors in Kakamega County, Kenya. Sci J Pub Health 2: 216-222.

16. Kennedy G, Ballard T, Dop MC (2011) Guidelines for measuring household and individual dietary diversity. Food and Agriculture Organization of the United Nations, Italy.

17. Israel GD (1992) Determining sample size. University of Florida, Cooperative Extension Service, Institute of Food and Agriculture Sciences, EDIS, United Nations.

18. Haftenberger M, Heuer T, Heidemann C, Kube F, Krem C, et al. (2010) Relative validation of a food frequency questionnaire for national health and nutrition monitoring. Nutr J 9: 36.

19. Dahl L, Mæland CA, Bjørkkjær T (2011) A short food frequency questionnaire to assess intake of seafood and $n-3$ supplements: validation with biomarkers. Nutr J 10: 127.

20. FAO, FANTA, FHI360 (2016) Minimum Dietary Diversity for Women: A Guide to Measurement. Rome, Italy.

21. Mbule MA, Byaruhanga YB, Kabahenda M, Lubowa A (2013) Determinants of anaemia among pregnant women in rural Uganda. Rural Remote Health 13: 2259.

22. Ibrahim ZM, El-Hamid SA, Mikhail H, Khattab MS (2011) Assessment of Adherence to Iron and Folic Acid Supplementation and Prevalence of Anemia in Pregnant Women. Med J Cairo Univ 79: 115-121.

23. Olatunbosun OA, Abasiattai AM, Bassey EA, James RS, Ibanga G, et.al (2014) Prevalence of Anemia among pregnant women at booking in the University of Uyo Teaching Hospital, Uyo, Nigeria. Biomed Res Int 2014: 849080.
24. Msuya SE, Hussein TH, Urey J, Sam NE, Stray-Pedersen B (2011) Anaemia among Pregnant Women in Northern Tanzania: Prevalence, Risk Factors and Effect on Perinatal Outcomes. Tanzan J Health Res 13: 33-39.

25. Abriha A, Yesuf ME, Wassie MM (2014) Prevalence and associated factors of anemia among pregnant women of Mekelle town: a cross sectional study. BMC Res Notes 7: 888 .

26. Abdelgader EA, Diab TA, Kordofani AA, Abdalla SE (2014) Haemoglobnin level, RBCs Indices, and iron status in pregnant females in Sudan. Basic Res J Med Clin Sci 3: 8-13.

27. Kennedy GL, Fanou-Fogny NML, Seghieri C, Brouwer ID (2009) Dietary diversity as a measure of the micronutrient adequacy of women's diets: results from Bamako, Mali site. Food and Nutrition Technical Assistance II Project. Washington, DC, USA.

28. Jayawardena R, Byrne NM, Soares MJ, Katulanda P, Yadav B, et al. (2013) High dietary diversity is associated with obesity in Sri Lankan adults: an evaluation of three dietary scores. BMC public health13: 314.

29. Mirmiran P, Azadbakht L, Azizi F (2006) Dietary diversity within food groups: an indicator of specific nutrient adequacy in Tehranian women. J Am Coll Nutr 25: 354-361.

30. Ruel M, Graham J, Murphy S, Allen L (2004) Validating simple indicators of dietary diversity and animal source food intake that accurately reflect nutrient adequacy in developing countries. Report submitted to GL-CRSP.

31. Addis Alene K, Mohamed Dohe A (2014) Prevalence of anemia and associated factors among pregnant women in an urban area of eastern Ethiopia. Anemia 2014: 561-567. 